\title{
AVALIAÇÃO ANTIMICROBIANA DA EFICÁCIA DOS EXTRATOS HIDROALCOÓLICOS DA PITANGUEIRA E DA GOIABEIRA, IN VITRO, CONTRA STAPHYLOCOCCUS AUREUS ISOLADOS DE MASTITE BOVINA
}

\author{
Alexandre Tourino Mendonça \\ Doutor em Ciências dos Alimentos pela Universidade Federal de Lavras (UFLA), \\ Lavras, MG, Brasil \\ alexandretourino@gmail.com \\ Glei dos Anjos de Carvalho Castro \\ Doutora em Ciências Veterinárias pela Universidade Federal de Lavras (UFLA), \\ Lavras, MG, Brasil \\ glei.castro@unincor.edu.br \\ Maria Clara Pereira Inácio \\ Graduando em Medicina Veterinária pela Universidade Vale do Rio Verde de Três Corações \\ (UNINCOR), Três Corações, MG, Brasil \\ mariaclarapereira325@gmail.com \\ Miriam de Andrade Pereira \\ Mestrado em Ciências Veterinárias pela Universidade Federal de Lavras (UFLA), \\ Lavras, MG, Brasil \\ miriam.pereira@unincor.edu.br
}

\begin{abstract}
RESUMO
A resistência bacteriana é motivo de preocupação para a medicina humana e veterinária, uma vez que se questiona a eficácia dos antibióticos disponíveis. Com isso pesquisa-se constantemente plantas com novos princípios ativos que combatam patógenos cada vez mais resistentes, como o Staphylococcus aureus. Nesse contexto, as árvores da família Myrtaceae, têm demonstrado potencial antimicrobiano, dentre elas a pitangueira (Eugenia uniflora L.) e a goiabeira (Psidium guajava L.) que foram objetos deste estudo realizado na UninCor de Três Corações, MG. Portanto, Objetivou-se testar a atividade antimicrobiana in vitro por determinação da Concentração Inibitória Mínima (CMI) dos extratos hidroalcoólicos frente às cepas de $S$. aureus isolados do leite de mastite bovina, e comparar com os antibióticos de uso comum. Os testes foram realizados em triplicata, com os extratos em concentrações de $100 \%$, $50 \%, 25 \%$ e 12,5\%, e comparados em dois períodos de preparação, 8 dias e com 3 meses. Baseado na estatística descritiva, o extrato hidroalcoolico da pitangueira na concentração de $100 \%$ nos dois tempos mostrou se mais eficiente, apresentado sensibilidade de $15,7 \%$ e 17,65\%, respectivamente frente a 9,8\% e 5,9\% da goiabeira na mesma concentração. Já ao se considerar os antibióticos Gentamicina, Norfloxacina, Amoxilina e Vancomicina, as sensibilidades foram de $100 \%, 100 \%, 88,2 \%$ e $29,4 \%$, ou seja, ação superior à da pitangueira e da goiabeira, sendo que a Norfloxacina e gentamicina mostraram maior eficiência em todas as cepas testadas. Portanto este estudo preliminar mostrou que os extratos hidroalcoólicos
\end{abstract}


AVALIAÇÃO ANTIMICROBIANA DA EFICÁCIA

DOS EXTRATOS HIDROALCÓLICOS DA PITANGUEIRA

E DA GOIABEIRA, IN VITRO, CONTRA

STAPHYLOCOCCUS AUREUS ISOLADOS DE MASTITE BOVINA
Alexandre Tourino Mendonça Glei dos Anjos de Carvalho Castro

Maria Clara Pereira Inácio Miriam de Andrade Pereira

aqui usados não foram eficientes contra $S$. aureus isolados de mastite bovina, entretanto futuros estudos abordando diferentes ensaios são necessários.

Palavras-Chave: Myrtaceae. Antimicrobiano. Norfloxacina.

\title{
EVALUATION OF ANTIMICROBIAL EFFICIENCY OF HYDROALCOHOLIC FROM EXTRACTS OF PITANGUEIRA AND GUAVA TREE, IN VITRO, AGAINST STAPHYLOCOCCUS AUREUS ISOLATED FROM BOVINE MASTITIS
}

\begin{abstract}
Bacterial resistance is a concern for human and veterinary medicine, since the effectiveness of the available antibiotics is being questioned. In this view, plants with new active ingredients that combat increasingly resistant pathogens, such as Staphylococcus aureus, are constantly being researched. In this context, the trees of the Myrtaceae family have shown antimicrobial potential, among them the pitangueira (Eugenia uniflora L.) and guava tree (Psidium guajava L.), which were the subjects of this study carried out at UninCor in Três Corações, MG. Therefore, the aim was to test the in vitro antimicrobial activity by determining the Minimum Inhibitory Concentration (MIC) of hydroalcoholic extracts against $S$. aureus strains isolated from bovine mastitis milk, and to compare them with commonly used antibiotics. The tests were performed in triplicate, with the extracts at concentrations of $100 \%, 50 \%, 25 \%$, and $12.5 \%$, and compared in two preparation periods, with 8 days and with 3 months. Based on descriptive statistics, the hydroalcoholic extract of pitangueira at $100 \%$ concentration in both times was more efficient, presenting sensibility of $15.7 \%$ and $17.65 \%$, respectively, against $9.8 \%$ and $5.9 \%$ of guava tree at the same concentration. When considering the antibiotics Gentamicin, Norfloxacin, Amoxillin and Vancomycin, the sensitivities were 100\%, 100\%, 88.2\% and $29.4 \%$, i.e., a higher action than in pitangueira and guava tree, with Norfloxacin and Gentamicin showing greater efficiency in all strains tested. Therefore, this preliminary study showed that the hydroalcoholic extracts used were not efficient against $S$. aureus isolated from bovine mastitis.
\end{abstract}

Keywords: Myrtaceae. Antimicrobial. Norfloxacin.

Recebido: $27 / 07 / 2020$. Aceito: 22/12/2020. 
AVALIAÇÃO ANTIMICROBIANA DA EFICÁCIA

DOS EXTRATOS HIDROALCÓLICOS DA PITANGUEIRA

E DA GOIABEIRA, IN VITRO, CONTRA

STAPHYLOCOCCUS AUREUS ISOLADOS DE MASTITE BOVINA
Alexandre Tourino Mendonça Glei dos Anjos de Carvalho Castro

Maria Clara Pereira Inácio Miriam de Andrade Pereira

\section{INTRODUÇÃO}

A resistência bacteriana é motivo de preocupação para a medicina humana e veterinária, uma vez que os antibióticos disponíveis já não são eficazes. Com isso pesquisa- se constantemente plantas com princípios ativos que combatam patógenos cada vez mais resistentes. De acordo com Freitas et al. (2013), o uso indiscriminado de antibióticos betalactâmicos sem realização de um antibiograma antes de iniciar a terapêutica está diretamente relacionado à presença de cepas de Staphylococcus aureus resistentes em animais domésticos e no homem. Diante deste problema a utilização de fitoterapia mostra uma potencial solução para o problema.

Dentre as famílias botânicas utilizadas como fitoterápicos, a Myrtaceae apresenta maior quantidade de elementos voláteis, com cerca de 3.500 espécies distribuídas mundialmente, tendo prevalência nas zonas tropicais e subtropicais da Austrália e América (STIEVEN; MOREIRA; SILVA, 2009).

Presentes na biodiversidade brasileira, as árvores conhecidas popularmente pela produção dos frutos e têm demonstrado potencial antimicrobiano, sendo objeto deste estudo a pitangueira (Eugenia unifloraL.) e a goiabeira (Psidium guajava L.).

A Eugenia unifloraL. apresenta-se como um arbusto ou árvore semidecídua, de 4 a $10 \mathrm{~m}$ de altura, copa estreita de tronco liso de cor pardo clara. As folhas são simples, cartáceas, de 3 a $7 \mathrm{~cm}$ de comprimento, com aroma característico. As flores são de cor branca, solitárias ou em grupos de 2-3 nas axilas nas extremidades dos ramos. Os frutos são do tipo drupa. Globosos e sulcados, brilhantes e de cor vermelha, amarela ou preta, com polpa carnosa e agridoce, contendo 1 a 2 sementes. Sua distribuição ocorre em todo o território brasileiro, podendo ser encontrada em abundância nos estados de Goiás, Bahia, Mato Grosso do Sul, Mato Grosso, Rio de Janeiro, São Paulo, Santa Catarina e Rio Grande do Sul (PRESTES, 2011; LORENZI; MATOS, 2008; LORENZONI et al., 2011).

De acordo com Mendonça (2016), os extratos de Eugenia uniflora L. são capazes de produzir substâncias com potencial antibiótico, utilizadas como mecanismo de defesa contra predação por microrganismos, insetos e herbívoros, devido a sua capacidade de produzir metabólitos secundários. Os metabólitos secundários sofrem influência e são afetados pelo meio externo e interno do vegetal como, por exemplo, espécie, variedade, estresse ambiental 
AVALIAÇÃO ANTIMICROBIANA DA EFICÁCIA

DOS EXTRATOS HIDROALCÓLICOS DA PITANGUEIRA

E DA GOIABEIRA, IN VITRO, CONTRA

STAPHYLOCOCCUS AUREUS ISOLADOS DE MASTITE BOVINA
Alexandre Tourino Mendonça Glei dos Anjos de Carvalho Castro

Maria Clara Pereira Inácio Miriam de Andrade Pereira

a que foi submetida à planta, estágios de crescimento e maturação, além da metodologia analítica empregada na determinação dos mesmos. (LORENZONI et al., 2013).

De acordo com Auricchio e Bacchi (2003), o óleo essencial da pitangueira tem efeito antimicrobiano frente a distintos microrganismos como Proteus vulgaris, Pseudomonas aeruginosa, Candida albicans e Trichophyton mentagrophytes. E esse potencial também está presente nos extratos das folhas que apresentam uma forte atividade antimicrobiana, sendo relatada atuando frente a bactérias Gram positivas, Gram negativas e fungos (HOLETZ et al. 2002).

Segundo Mendonça (2016), através da avaliação da concentração mínima inibitória (CMI), o extrato hidroalcoólico se destacou pela inibição do crescimento do Staphylococcus aureus. Já o extrato bruto apresentou a mesma concentração inibitória mínima para as cepas de Pseudomonas sp., Staphylococcus aureus e Escherichia coli.

A Psidium guajava L. é uma planta amplamente distribuída no território nacional e bem adaptada, popularmente chamada de goiabeira, é uma árvore frutífera de copa aberta, de até $7 \mathrm{~m}$ de altura, nativa da América do Sul, presente desde a Venezuela até o Rio de Janeiro e cultivada em todo o país. É utilizada de forma caseira no tratamento de diarreia na infância, devido a ação da quercetina, principal flavanóide constituinte da folha de goiabeira, que tem um efeito antipropulsor do trânsito intestinal e reduz a permeabilidade dos capilares abdominais (ZHANG et al., 2003). Há também relatos do uso do chá em bochechos e gargarejos nos casos de estomatites e faringites (LORENZI; MATOS, 2008).

Alguns estudos comprovaram o efeito antimicrobiano e antidiarreico de plantas da família Myrtaceae, Chah et al. (2006) relataram efeito antibacteriano de extratos metanólicos da goiabeira frente a diversas espécies bacterianas, entre elas a Escherichia coli, principal bactéria causadora de diarreia em recém-nascidos. (PRESTES, 2011).

O Staphylococcus aureus subsp. aureus (S. aureus) pertence ao gênero Staphylococcus e a família Staphylococcaceae. O S. aureus foi primeiramente descrito por Sir Alexander Ogston em 1882 e dois anos mais tarde, Rosenbach isolou em uma cultura pura e introduziu o nome S. aureus. O nome do organismo é derivado de palavras gregas staphyle (um cacho de uvas) e cocos (grãos ou baga). Este microrganismo é uma bactéria gram-positiva, anaeróbia facultativa, catalase-positiva, oxidase-negativa, DNase positiva, sem motilidade e não formadora de esporos. (SANTANA, 2015). 
AVALIAÇÃO ANTIMICROBIANA DA EFICÁCIA

DOS EXTRATOS HIDROALCÓLICOS DA PITANGUEIRA

E DA GOIABEIRA, IN VITRO, CONTRA

STAPHYLOCOCCUS AUREUS ISOLADOS DE MASTITE BOVINA
Alexandre Tourino Mendonça Glei dos Anjos de Carvalho Castro

Maria Clara Pereira Inácio Miriam de Andrade Pereira

De acordo com List of prokaryotic names há 69 espécies e 30 subespécies de Staphylococcus divididas em duas categorias: coagulase positivas e coagulase negativas (PARTE et al., 2020). Essa divisão é baseada na capacidade de coagulação do plasma, que é uma propriedade considerada importante como marcador de patogenicidade dos estafilococos (BEHME et al., 1996).

Os principais substratos utilizados por este organismo são os açúcares (glucose, frutose, galactose, manose, ribose, maltose, sacarose, trealose), álcoois (manitol), ácidos orgânicos (acetato), e em algumas condições aminoácidos (glutamina, arginina). Uma característica que distingue o S. aureus de outras bactérias patogênicas é a sua elevada tolerância a baixos valores de atividade de água e concentrações de $\mathrm{NaCl}$ até $20 \%$ (halotolerantes) (SANTANA, 2015).

Os S. aureus são mesófilos com temperatura ótima de crescimento entre $37^{\circ} \mathrm{C}$ a $40^{\circ} \mathrm{C}$, e temperatura mínima para o crescimento de cerca de $7,0^{\circ} \mathrm{C}$. São capazes de crescer numa faixa de $\mathrm{pH} 4,0-9,8$, com um pH ótimo entre 6-7. Esta bactéria sobrevive ao congelamento em carnes a $-18^{\circ} \mathrm{C}$ por aproximadamente seis meses, sem qualquer alteração nas contagens de UFC. Enquanto em temperaturas superiores a $46^{\circ} \mathrm{C}$ a maioria é inativada, com algumas exceções que crescem até $50^{\circ} \mathrm{C}$. Porém, as enterotoxinas podem resistir tanto ao processo de pasteurização quanto ao de esterilização de leite e de alimentos enlatados, e não são afetados mesmo que por uma dose de esterilização de radiação (MEDVEĎOVÁ; VALÍk, 2012).

Também é encontrado em úberes de fêmeas bovinas lactantes e canais dos tetos, constituindo-se em um dos principais agentes etiológicos da mastite contagiosa. E existindo a possibilidade do contato direto entre animais positivos e seres humanos imunossuprimidos, esses podem desenvolver infecções de difícil tratamento. (ASSUNÇÃO, 2001; MENDONÇA, 2004; FREITAS et al., 2013).

Assim como afirma Santos et al. (2007), o mecanismo de invasão do S. aureus ocorre a partir da aderência à pele ou mucosa, prosseguindo-se do rompimento do epitélio parasitado e de ligações intercelulares. Logo após, o microrganismo adota estratégias de evasão a opsonização pelo complemento, e a fagocitose e reduzindo a resposta imunológica pelo organismo do hospedeiro.

Assim, procurou-se por Determinação da Concentração Inibitória Mínima (CIM) avaliar a atividade antimicrobiana dos extratos hidroalcoólicos dos caules e folhas secas de 
AVALIAÇÃO ANTIMICROBIANA DA EFICÁCIA

DOS EXTRATOS HIDROALCÓLICOS DA PITANGUEIRA

E DA GOIABEIRA, IN VITRO, CONTRA

STAPHYLOCOCCUS AUREUS ISOLADOS DE MASTITE BOVINA
Alexandre Tourino Mendonça Glei dos Anjos de Carvalho Castro

Maria Clara Pereira Inácio Miriam de Andrade Pereira

goiabeira e pitangueira, contra S. aureus, isolados de mastite bovina assim como comparar a eficiência encontrada a antibióticos utilizados na bovinocultura leiteira.

\section{MATERIAL E MÉTODOS}

\subsection{Local de realização dos testes}

A pesquisa foi desenvolvida no Laboratório de Pesquisa I e no Laboratório de Microbiologia da Universidade Vale do Rio Verde - UninCor de Três Corações, Minas Gerais.

\subsection{Coleta de folhas e caules de Myrtaceae}

A colheita das folhas foi realizada segundo Prestes (2011), de árvores previamente identificadas com os nomes científicos e populares das plantas, na Fazenda Experimental da UninCor, localizada no bairro Cinturão Verde em Três Corações - MG no período de junho/2017. Posteriormente, folhas e caules foram lavadas e higienizadas com hipoclorito de sódio e acondicionadas em sacos de papel por três dias a temperatura de 30 ํ em estufa com aeração (MENDONÇA, 2016).

\subsection{Microrganismo testado}

As bactérias testadas foram foram isoladas de amostras de leite coletadas de animais diagnosticados com mastite a partir de triagem preventiva específica para detectar $S$. aureus em fazendas da região de Três Corações e em Carmo de Minas - MG. O controle positivo utilizado foi e a cepa controle ATCC 29213.

\subsubsection{Coleta e processamento do material}

Foram coletadas e analisadas 70 amostras de leite proveniente de fêmeas bovinas da raça Holandesa e seus cruzamentos, diagnosticadas com mastite a partir do controle da qualidade de leite realizado em propriedades localizadas no município de Três Corações, durante o período entre junho e setembro de 2017. 
AVALIAÇÃO ANTIMICROBIANA DA EFICÁCIA

DOS EXTRATOS HIDROALCÓLICOS DA PITANGUEIRA

E DA GOIABEIRA, IN VITRO, CONTRA

STAPHYLOCOCCUS AUREUS ISOLADOS DE MASTITE BOVINA
Alexandre Tourino Mendonça Glei dos Anjos de Carvalho Castro

Maria Clara Pereira Inácio

Miriam de Andrade Pereira

O processo de coleta iniciou-se com a devida antissepsia das mãos do ordenhador com água e sabão, que a seguir realizou o teste da caneca telada, pós pré-dipping e secagem com papel toalha. Aplicou-se álcool 70\% no esfíncter do teto, descartando-se os três primeiros jatos de leite e coletando-se cerca de $10 \mathrm{ml}$ de leite em tubo estéril. As amostras com identificação do animal foram acondicionadas em caixa isotérmica, transportada sob refrigeração de 4으 C, e no Laboratório de Microbiologia da Universidade Vale do Rio Verde Unincor, foram congeladas em uma temperatura média de -60 C visando conservar as amostras e, posteriormente realizou o descongelamento à temperatura ambiente para o cultivo microbiológico e análises bioquímicas.

\subsection{Isolamento do Staphylococcus aureus}

As amostras foram inoculadas em Ágar Baird Parker, enriquecido com gema de ovo com telurito de potássio, e incubadas a $37^{\circ} \mathrm{C}$ por 48 horas. As colônias caracterizadas como Staphylococcus spp. (colônias de cor negra, brilhantes, com zona de precipitação circundada por halo claro) foram submetidas à coloração de Gram e testes para a identificação da espécie S. aureus (prova da catalase, prova da coagulase e fermentação do manitol) (SAEKI, 2011).

\subsubsection{Preparação dos extratos hidroalcoólicos (EHA)}

Os EHA foram preparados da seguinte maneira: 50 gramas das folhas previamente secas e trituradas, foram homgenizadas a álcool 70\%, para início do processo da maceração. O extrato foi acondicionado em recipiente estéril de vidro âmbar, durante oito dias, em temperatura ambiente, ao abrigo de luz e umidade, com agitações periódicas. Logo após, iniciou-se o processo de filtração e acondicionamento em vidro âmbar, sob o abrigo de luz e umidade, em temperatura ambiente (NASCIMENTO, 2013).

Os testes antimicrobianos foram realizados em dois períodos, o primeiro após 8 dias de produção do extrato e o segundo após 3 meses. Além disso, foram realizados antibiogramas com 4 drogas convencionais frente às 17 cepas isoladas e a cepa controle. Os antibióticos avaliados pelo teste de difusão em disco foram Norfloxacina, Gentamicina, Amoxilina e Vancomicina. 
AVALIAÇÃO ANTIMICROBIANA DA EFICÁCIA

DOS EXTRATOS HIDROALCÓLICOS DA PITANGUEIRA

E DA GOIABEIRA, IN VITRO, CONTRA

STAPHYLOCOCCUS AUREUS ISOLADOS DE MASTITE BOVINA
Alexandre Tourino Mendonça Glei dos Anjos de Carvalho Castro

Maria Clara Pereira Inácio Miriam de Andrade Pereira

\subsection{Diluição dos extratos}

A diluição foi preparada em quatro tubos de ensaio estéreis $(10 \mathrm{~mL})$, identificados com suas respectivas concentrações. No primeiro tubo (vazio e estéril) adicionou-se $2 \mathrm{ml}$ do extrato puro (100\%) com auxílio de pipetas e ponteiras estéreis, em seguida retirou-se $1 \mathrm{ml}$ do primeiro tubo que foi adicionada ao segundo tubo contendo $1 \mathrm{ml}$ de solução salina $0,9 \%$ (concentração $50 \%$ de extrato), assim seguiu-se a diluição até o tubo quatro com concentração de 12,5\% (MENDONÇA, 2016). Esse processo foi realizado e testado frente ao S. aureus em dois tempos, o primeiro com 8 dias e o segundo, após 3 meses do extrato preparado e mantido sob abrigo de luz, buscando-se avaliar possível mudança da eficácia dos extratos.

\subsection{Preparação dos inóculos}

Os inóculos foram preparados e padronizados em solução fisiológica esterilizada, comparando-se a turbidez com o tubo no 0,5 da escala MC Farland a fim de se obter cerca de 106 UFC/ml (MENDONÇA, 2016).

\subsection{Difusão em disco e teste antimicrobiano dos extratos}

Na placa de Petri contendo Ágar Mueller Hinton como meio de cultura, espalhou-se, com o auxílio de "swabs" estéreis o inóculo bacteriano preparado com a solução salina estéril (com turvação 0,5 da escala de Mac Farland) e distribui-se uniformemente sobre a superfície do Ágar (SILVEIRA, 2009).

Na placa de Petri identificaram-se os locais onde foram alocados os discos de papel filtro estéreis impregnados (mergulhando os discos no extrato por 30 segundos) com o extrato em diferentes concentrações (STIEVEN; MOREIRA; SILVA, 2009), com espaço de 20mm entre os discos EHA e dos antibióticos Norfloxacina, Gentamicina, Amoxilina e Vancomicina e 15mm da borda externa da placa, realizou-se a distribuição dos discos com ajuda de uma pinça estéril. Em seguida, com as placas já estriadas e com os discos, as placas invertidas foram incubadas a $37^{\circ} \mathrm{C}$, por 24 horas, e após este período medidas as zonas de inibição, em milímetro. Todos os isolados, assim como a cepa controle foram testadas em triplicata. 
AVALIAÇÃO ANTIMICROBIANA DA EFICÁCIA

DOS EXTRATOS HIDROALCÓLICOS DA PITANGUEIRA

E DA GOIABEIRA, IN VITRO, CONTRA

STAPHYLOCOCCUS AUREUS ISOLADOS DE MASTITE BOVINA
Alexandre Tourino Mendonça Glei dos Anjos de Carvalho Castro

Maria Clara Pereira Inácio Miriam de Andrade Pereira

O resultado final foi determinado por estatística descritiva comparativa a partir dos halos de inibição do crescimento $(\mathrm{mm})$ encontrados, utilizando paquímetro universal para medir os halos formados (MENDONÇA, 2016).

\section{RESULTADOS E DISCUSSÃO}

Das 70 amostras provenientes de leite bovino de duas propriedades, conseguiu-se ao final de todos os testes bioquímicos e microbiológicos o isolamento de 17 cepas de S.aureus coagulase positiva. Sendo essas utilizadas em triplicata nos testes antimicrobianos, e tendo como cepa controle a S. aureus ATCC 29213 para controlar a precisão da reprodutibilidade e dos testes de disco-difusão.

A partir do controle realizado com a solução salina estéril e álcool 70\%, foi possível afirmar que estes não interferiram na ação dos extratos de pitangueira e goiabeira. Além disso, foram realizadas placas controles apenas com o meio ágar Mueller Hinton e também com cepas, certificando-se que as amostras controles foram efetivas na verificação de contaminação cruzada, não havendo crescimento de outras colônias bacterianas.

Os resultados obtidos nos ensaios de difusão em discos realizados com os extratos de pitangueira e goiabeira foram positivos (Figuras 1 e 2 ) houve atividade antimicrobiana frente Staphylococcus aureus, visto que após leitura da placa foi possível observar halos com diversos diâmetros, inclusive superiores a $8 \mathrm{~mm}$, como o preconizado por Mendonça (2016).

Figura 1 - (A) Cepa de mastite bovina, halos de inibição da Norfloxacina, Gentamicina e Amoxilina, sem inibição da Vancomicina; (B) Cepa controle ATCC 29213, halos de inibição frente aos mesmos antibióticos.

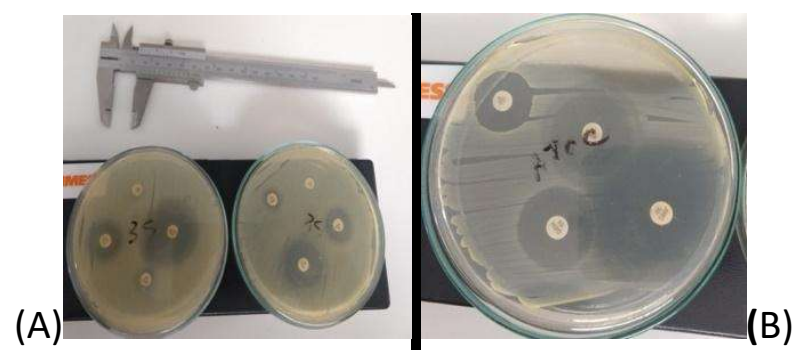

Fonte: Autores (2021).

Figura 2 - (A)(B) Cepas de mastite bovina, halos de inibição do extrato da pitangueira; (C) Cepas de mastite bovina, ausência de halos de inibição do extrato da goiabeira; (D) Cepa controle ATCC 29213, halos de inibição frente ao extrato da pitangueira. 
AVALIAÇÃO ANTIMICROBIANA DA EFICÁCIA DOS EXTRATOS HIDROALCÓLICOS DA PITANGUEIRA

E DA GOIABEIRA, IN VITRO, CONTRA

STAPHYLOCOCCUS AUREUS ISOLADOS DE MASTITE BOVINA
Alexandre Tourino Mendonça Glei dos Anjos de Carvalho Castro

Maria Clara Pereira Inácio Miriam de Andrade Pereira

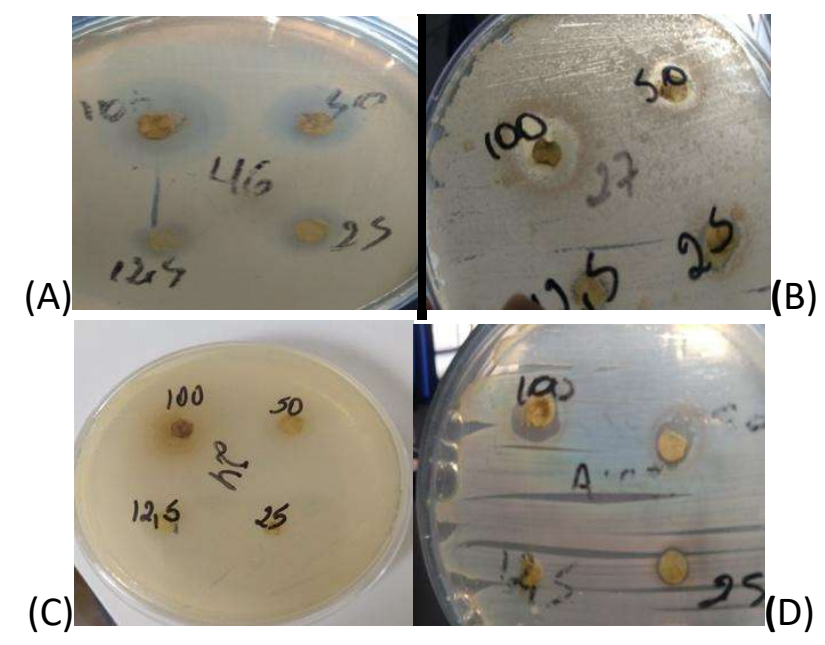

Fonte: Autores (2021).

Nos gráficos (1, 2, 3 e 4) são apresentados os resultados obtidos nos testes antimicrobianos dos extratos hidroalcoólicos da pitangueira e da goiabeira frente às cepas de S. aureus isoladas de mastite e a cepa controle ATCC.

Gráfico 1 - Porcentagem de cepas com halos superiores a 8 mm de diâmetro, considerando 51 placas.

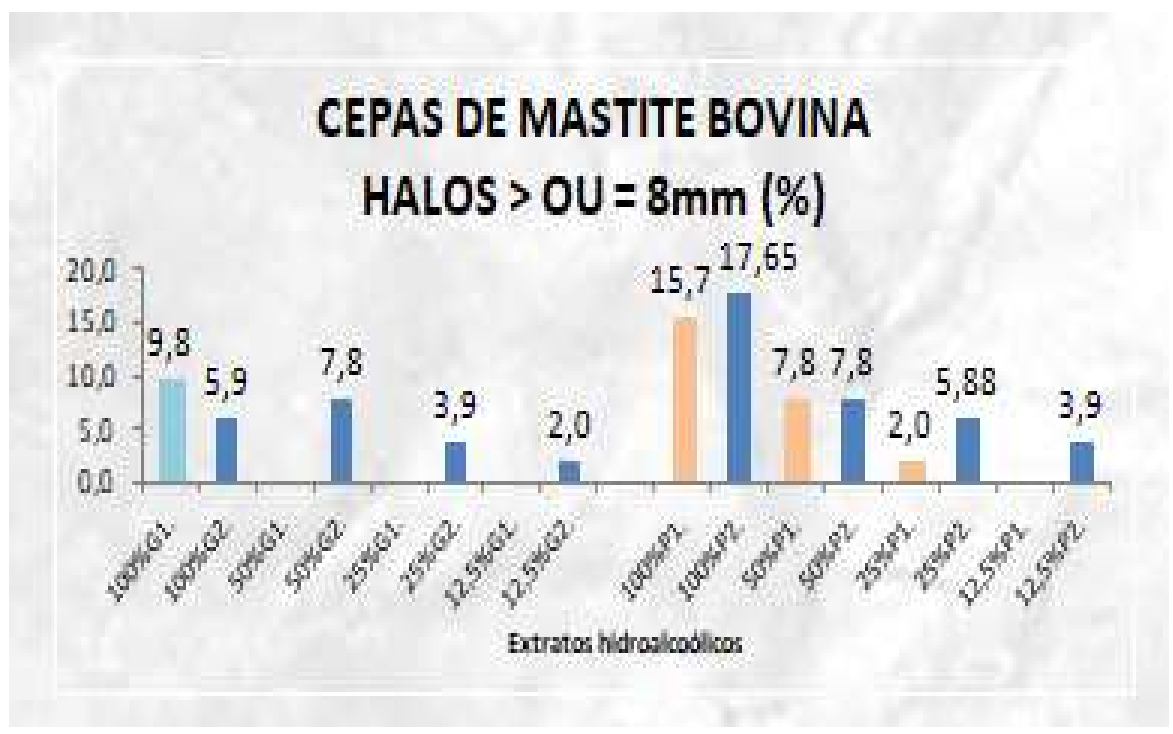

Fonte: Autores (2021)

Gráfico 2 - Porcentagem de cepas com halos superiores a $8 \mathrm{~mm}$ de diâmetro, considerando a cepa controle em triplicata. 
AVALIAÇÃO ANTIMICROBIANA DA EFICÁCIA

DOS EXTRATOS HIDROALCÓLICOS DA PITANGUEIRA

E DA GOIABEIRA, IN VITRO, CONTRA

STAPHYLOCOCCUS AUREUS ISOLADOS DE MASTITE BOVINA
Alexandre Tourino Mendonça Glei dos Anjos de Carvalho Castro

Maria Clara Pereira Inácio Miriam de Andrade Pereira

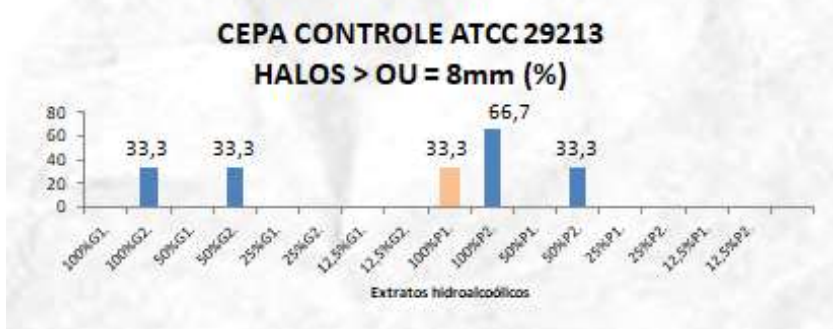

Fonte: Autores (2021).

A seguir tem-se a média de diâmetro dos halos que foram superiores a $8 \mathrm{~mm}$.

Gráfico 3 - Ação dos extratos hidroalcoólicos frente às 17 cepas isoladas de S. aureus, considerando a média dos halos superiores a $8 \mathrm{~mm}$.

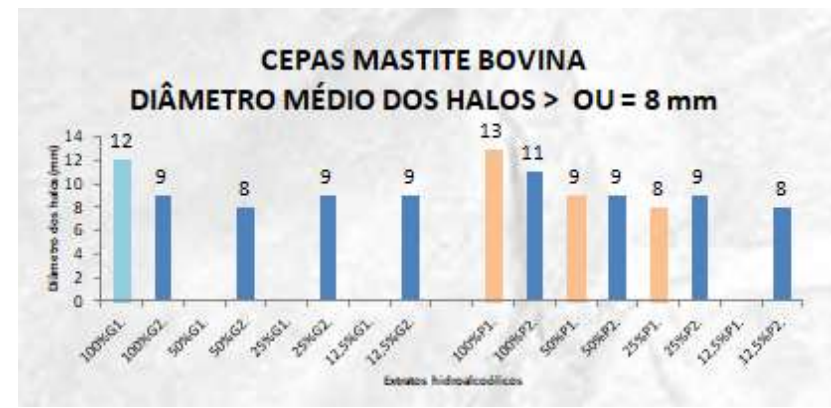

Fonte: Autores (2021).

Gráfico 4 - Ação dos extratos hidroalcoólicos frente à cepa controle.

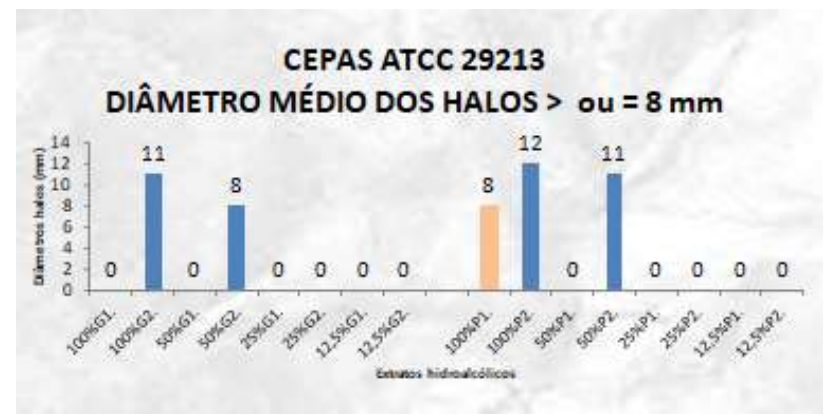

Fonte: Autores (2021).

Ao se considerar a média de todos os diâmetros formados com os extratos hidroalcoólicos, os valores apresentam grande redução, tanto na cepa controle como nas isoladas de mastite, isso se explica pela dispersão de valores encontrados nas 51 placas analisadas, o que resulta um acentuado desvio padrão, como observado a seguir (gráficos 5, 6 e 7). 
AVALIAÇÃO ANTIMICROBIANA DA EFICÁCIA

DOS EXTRATOS HIDROALCÓLICOS DA PITANGUEIRA

E DA GOIABEIRA, IN VITRO, CONTRA

STAPHYLOCOCCUS AUREUS ISOLADOS DE MASTITE BOVINA
Alexandre Tourino Mendonça Glei dos Anjos de Carvalho Castro

Maria Clara Pereira Inácio

Miriam de Andrade Pereira

Gráfico 5 - Considerando os 51 valores encontrados desde 0 até os superiores a $8 \mathrm{~mm}$, o que acaba reduzindo muito a média geral.

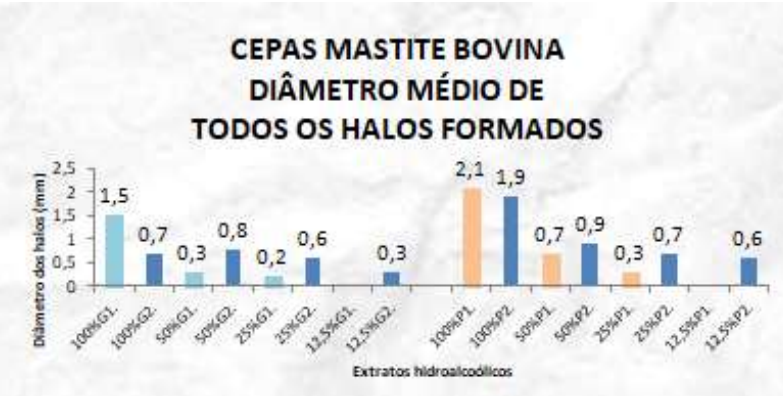

Fonte: Autores (2021).

Gráfico 6 - Demonstrando as médias e os desvios encontrados nos testes com extratos hidroalcoólicos.

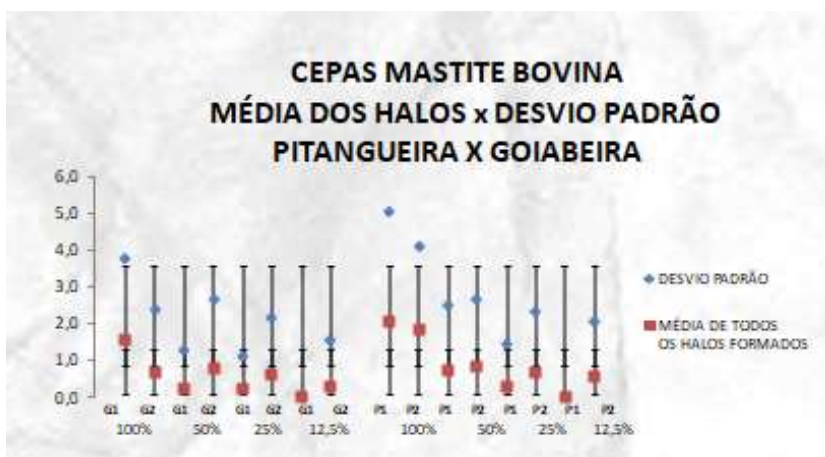

Fonte: Autores (2021).

Gráfico 7 - Cepa controle com diâmetro dos halos reduzidos quando considerados todos os valores.

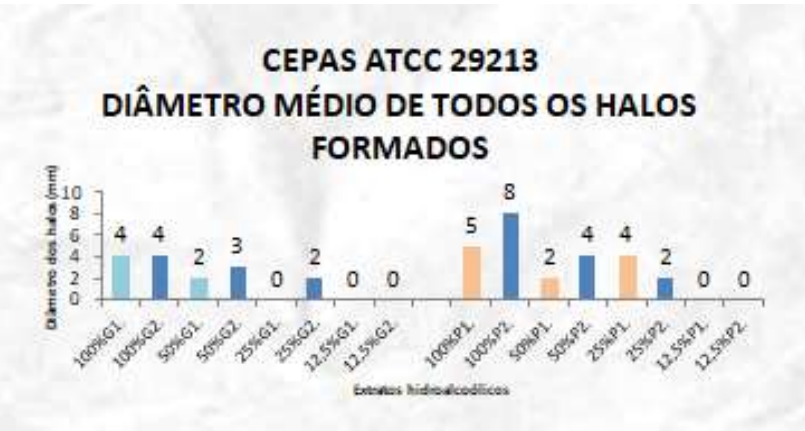

Fonte: Autores (2021).

A partir desses dados apresentados pode se observar que a pitangueira na concentração de $100 \%$ apresentou ação superior a goiabeira em qualquer concentração, 
AVALIAÇÃO ANTIMICROBIANA DA EFICÁCIA

DOS EXTRATOS HIDROALCÓLICOS DA PITANGUEIRA

E DA GOIABEIRA, IN VITRO, CONTRA

STAPHYLOCOCCUS AUREUS ISOLADOS DE MASTITE BOVINA
Alexandre Tourino Mendonça Glei dos Anjos de Carvalho Castro

Maria Clara Pereira Inácio Miriam de Andrade Pereira

sendo as cepas de mastite mais sensíveis à pitangueira com 8 dias de extrato e as cepas controles mais sensíveis ao extrato com 3 meses. Porém, ao analisar a abrangência de cepas sensíveis (\% de cepas com halos > ou = a $8 \mathrm{~mm}$ ), a pitangueira com 3 meses é mais eficaz, atingindo mais cepas de mastite bovina e também a controle. Essa eficácia da Eugenia uniflora também foi relatada por Duarte (2006) que testou substâncias reconhecidas cientificamente como 1,8-cineol, limoneno e linalol, geranial, germacreno-D e mentol que são produtos do metabolismo secundário da planta. Supõe-se que a ação antimicrobiana é mais eficaz no extrato com 3 meses devido uma maior concentração desses metabólitos, portanto novos estudos avaliando as substâncias presentes e o tempo para concentração são necessários .

Apesar de a cepa controle ter mostrado uma CIM de 25\% dos extratos da pitangueira e da goiabeira, os halos formados na presença do EHA apresentam média superior aos presentes nas 17 cepas de S. aureus (CIM de 12,5\%), e todos os antibióticos formaram halo de inibição na cepa controle ATCC 29213, o que sugere os isolados deste estudo são mais resistentes que a amostra ATCC utilizada como controle positivo.

Prestes (2011), ao testar os EHA obtidos de folhas secas durante o período de repouso como o realizado nesta pesquisa, encontrou CIM de $12,5 \%$ da pitangueira e $6,25 \%$ da goiabeira frente ao S. aureus ATCC 12600, o que revela uma sensibilidade ainda maior que a cepa ATCC 29213 utilizada nesse trabalho. E este autor ainda afirma que se tem CIM ainda mais reduzida quando realizados testes na época de floração com folhas secas da pitangueira (CMI 6,25\%) e frescas da goiabeira (CMI 3,125\%).

Apesar de mostrar a capacidade de inibição, os EHA aqui testados inibiram isolados neste trabalho, e os valores apresentados nos halos de inibição do teste de difusão em disco foram muito inferiores aos encontrados perante Norfloxacina, Gentamicina, Amoxilina e Vancomicina.

Ao analisar a eficácia dos antibióticos convencionais, a Norfloxacina e a Gentamicina obtiveram $100 \%$ de sensibilidade frente às 17 cepas de mastite bovinas e a cepa controle. Já a Amoxilina e a Vancomicina agiram com sensibilidade de $100 \%$ na cepa controle, mas com 79,4 e $29,4 \%$ nos isolados de mastite bovina, indicando-se resistência, como se pode observar a seguir (Gráfico 8).

Gráfico 8 - Cepas de mastite bovina e a cepa controle demonstraram sensibilidade aos antibióticos convencionais. 
AVALIAÇÃO ANTIMICROBIANA DA EFICÁCIA

DOS EXTRATOS HIDROALCÓLICOS DA PITANGUEIRA

E DA GOIABEIRA, IN VITRO, CONTRA

STAPHYLOCOCCUS AUREUS ISOLADOS DE MASTITE BOVINA
Alexandre Tourino Mendonça Glei dos Anjos de Carvalho Castro

Maria Clara Pereira Inácio Miriam de Andrade Pereira

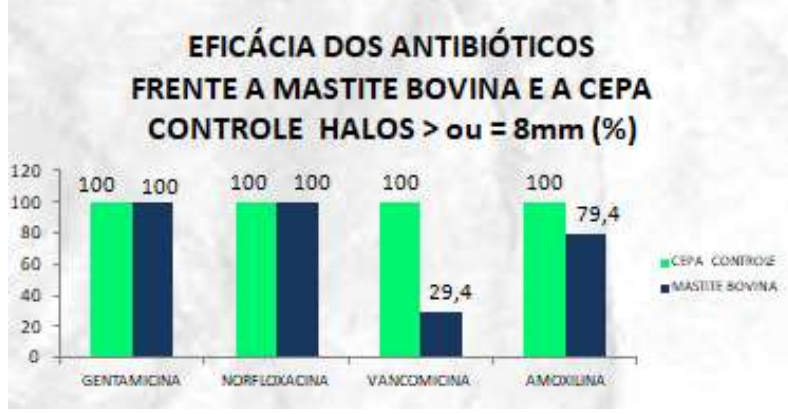

Fonte: Autores (2021).

Ao analisar o diâmetro médio de todos os halos formados frente aos 4 antibióticos, a cepa controle ATCC 29213 foi a mais sensível frente a todos, exceto a Norflaxacina, no qual se observou diferença de $2,5 \mathrm{~mm}$ em relação às médias dos halos formados nas cepas de $S$. aureus isoladas de mastite bovina (gráfico 9).

Gráfico 9 - Diâmetro médio de todos os halos formados nas cepas de mastite bovina e a cepa controle.

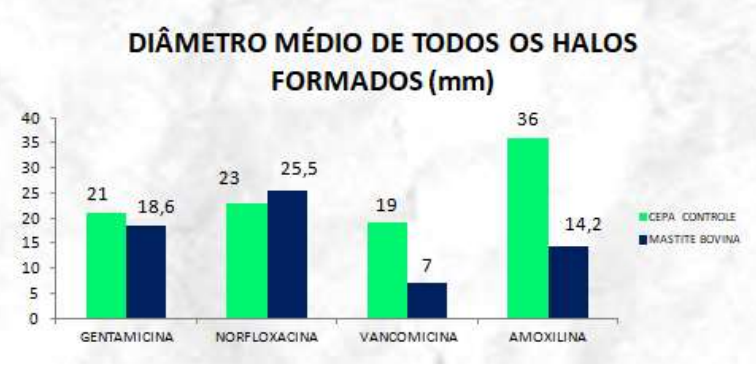

Fonte: Autores (2021).

E ao observar a ação dos antibióticos frente as 51 placas de $S$. aureus, obteve-se média alta e valor reduzido de desvio padrão nos resultados de sensibilidade obtidos frente à Gentamicina e à Norfloxacina. Entretanto, na Amoxicilina o desvio padrão aumenta e se aproxima da média por já ter um nível de resistência (20,6\%). E nos dados observados na Vancomicina a situação se inverte, a média apresentada é menor que o desvio (Gráfico 10), o que se justifica por alta resistência $(70,6 \%)$ e por halos que variam de 0 a $27 \mathrm{~mm}$.

Gráfico 10 - Demonstra o desvio padrão e a média de todos os halos formados pelos 4 antibióticos frente as 17 cepas de $S$. aureus isolados de mastite bovina. 
AVALIAÇÃO ANTIMICROBIANA DA EFICÁCIA

DOS EXTRATOS HIDROALCÓLICOS DA PITANGUEIRA

E DA GOIABEIRA, IN VITRO, CONTRA

STAPHYLOCOCCUS AUREUS ISOLADOS DE MASTITE BOVINA
Alexandre Tourino Mendonça Glei dos Anjos de Carvalho Castro

Maria Clara Pereira Inácio Miriam de Andrade Pereira

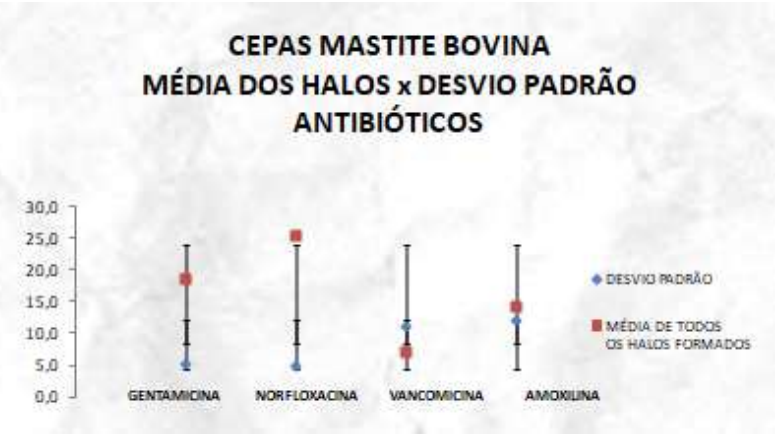

Fonte: Autores (2021).

Dentre as classes dos antibióticos testados nesse trabalho, foi observado a eficiência de Quinolona (Norfloxacina na concentração de $10 \mu \mathrm{g}$ ), no Aminoglicosídeo (Gentamicina 10 $\mu \mathrm{g}$ ), e logo após no $\beta$ - Lactâmico (Amoxicilina $30 \mu \mathrm{g}$ ) e com resultados mínimos no Glicopeptídeo (Vancomicina $30 \mu \mathrm{g}$ ), respectivamente. Sendo a sensibilidade baixa das cepas de $S$. aureus isoladas de mastite bovina provavelmente pelo fato dos dois últimos antibióticos citados terem mecanismo de ação na parede celular do agente, alterando apenas o sítio onde ocorre a inibição da síntese. Já a Norfloxacina age inibindo a síntese da Dna- girase das bactérias e a Gentamicina impede a síntese proteica bacteriana no ribossomo, mecanismos esses que demonstraram maior eficácia na ação antimicrobiana ao $S$. aureus isolado de mastite bovina (NCCLS, 2003).

De acordo com NCCLS (2003) a Vancomicina seria indicada a cepas gram-positivas resistentes aos $\beta$ - lactâmicos como os $S$. aureus resistentes à Meticilina (MRSA). Porém, frente às cepas testadas e a cepa controle ATCC 29213, os halos de inibição formados pela Amoxicilina são quase o dobro dos encontrados na Vancomicina. Porém isto não tem inferência científica já que o padrão de susceptibilidade destes antimicrobianos podem ser distintos.

Durante a pesquisa, constatou-se 4 cepas resistentes à Vancomicina, e sensíveis à pitangueira, e 3 dessas também a goiabeira. Um dado importante que demonstra uma alternativa futura de estudo, como se pode observar a seguir (gráfico 11).

Gráfico 11 - Cepas resistentes à Vancomicina, mas com sensibilidade à pitangueira e à goiabeira. 
AVALIAÇÃO ANTIMICROBIANA DA EFICÁCIA

DOS EXTRATOS HIDROALCÓLICOS DA PITANGUEIRA

E DA GOIABEIRA, IN VITRO, CONTRA

STAPHYLOCOCCUS AUREUS ISOLADOS DE MASTITE BOVINA
Alexandre Tourino Mendonça Glei dos Anjos de Carvalho Castro Maria Clara Pereira Inácio Miriam de Andrade Pereira

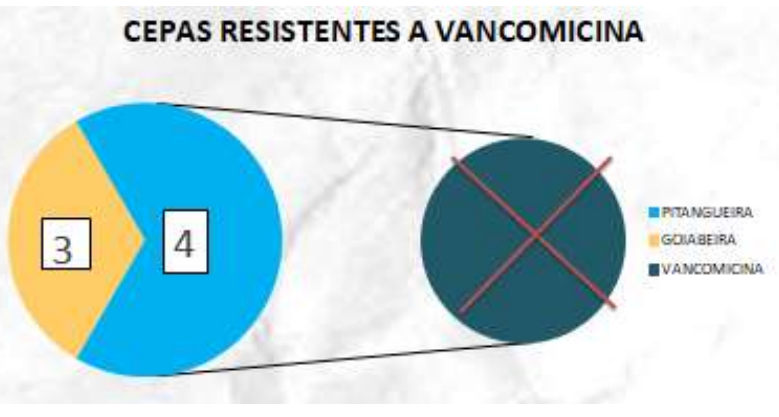

Fonte: Autores (2021).

Perante a resistência demonstrada à Vancomicina, uma alternativa seria como o realizado por Maia et al. (2009), que associou as folhas da goiabeira com a Norfloxacina em amostras de $S$. aureus isolados de bovinos, onde das 10 amostras utilizadas a CMI do antibiótico isolado foi de 1:2 e quando associado à Psidium guajava observou-se ação microbiana em diluições de 1:16 à 1:64. Já Coutinho et al. (2011) testou o efeito de Gentamicina associado ao extrato de Eugenia unifloraconseguindo diminuir a CMI de 8 para 4 $\mu \mathrm{g} / \mathrm{ml}$ na inibição de S.aureus SA358 resistentes a aminoglicosídeos. Diante dessas pesquisas é possível afirmar que existe efeito sinérgico. Assim, a associação das plantas da família Myrtaceae com antibióticos podem ser uma opção terapêutica para tratar infecções causadas por S.aureus.

\section{CONCLUSÕES}

Os extratos hidroalcoólicos da pitangueira (Eugenia unifloraL.) e da goiabeira (Psidium guajava L.) mostraram ação antimicrobiana nos isolados de S. aureus testados, sendo a pitangueira mais eficaz porém menos eficientes que os antibióticos tradicionais. Ao se abordar a concentração mínima inibitória para Staphylococcus aureus isolados de mastite bovina, tanto a goiabeira como a pitangueira apresentaram $\mathrm{CMI} 12,5 \%$, e frente à cepa controle elas apresentaram CIM de 25\%. Destacando-se assim, que existe potencial antimicrobiano, mas limitado principalmente ao se pensar no uso no campo veterinário.

\section{AGRADECIMENTOS}


AVALIAÇÃO ANTIMICROBIANA DA EFICÁCIA

DOS EXTRATOS HIDROALCÓLICOS DA PITANGUEIRA

E DA GOIABEIRA, IN VITRO, CONTRA

STAPHYLOCOCCUS AUREUS ISOLADOS DE MASTITE BOVINA
Alexandre Tourino Mendonça Glei dos Anjos de Carvalho Castro

Maria Clara Pereira Inácio

Miriam de Andrade Pereira

Agradecemos a FAPEMIG pela bolsa de pesquisa concedida, a UninCor pelos laboratórios e materiais disponibilizados e ao professor Geraldo Márcio da Costa (UFLA) por nos ter cedido a cepa controle.

\section{REFERÊNCIAS}

ASSUNÇÃO, E. G. Identificação dos pontos de contaminação microbiana ao logo do processamento de queijo prato: estudo de caso. 2001. Dissertação (Mestrado em Microbiologia de Alimentos) - Universidade Federal de Lavras, Lavras, 2001.

AURICCHIO, Mariangela T.; BACCHI, Elfried M. Fo-lhas de eugenia uniflora L. (pitanga: propriedades farmacobotânicas, químicas e farmacológicas. Rev. Inst. Adolfo Lutz, [S. I.], p. 55-61, 2003.

BEHME, Ronald J. et al. Identification of staphylococci with a self-educating system using fatty acid analysis and biochemical tests. Journal of clinical microbiology, [S. I.], v. 34, n. 12, p. 30753084, 1996.

$\mathrm{CHAH}, \mathrm{K}$. F. et al. Antibacterial and wound healing properties of methanolic extracts of some Nigerian medicinal plants. Journal of Ethnopharmacology, [S. I.], v. 104, n. 1-2, p. 164-167, 2006.

COUTINHO, H. et al. Fruits to potentiate the antibiotic activity: the effect of Eugenia unifloraand Eugenia jam-bolanum L. against MRSA. Acta alimentaria, [S. I.], v. 41, n. 1, p. 6772, 2011.

DUARTE, Marta Cristina Teixeira. Atividade antimicrobiana de plantas medicinais e aromáticas utilizadas no Brasil. Revista MultiCiência, [S. I.], v. 7, n. 1, p. 1-16, 2006.

FREITAS, A. B. et al. Staphylococcus aureus resistentes em animais de companhia. Revista Eletrônica Novo Enfoque, [S. I.], v. 16, n. 16, p. 95-101, 2013.

HOLETZ, Fabíola Barbiéri et al. Screening of some plants used in the Brazilian folk medicine for the treatment of infectious diseases. Memórias do Instituto Oswaldo Cruz, [S. I.], v. 97, n. 7, p. 1027-1031, 2002.

PARTE, A. C.; SARDÀ CARBASSE, J.; MEIER-KOLTHOFF, J. P.; REIMER, L. C.; GÖKER, M. List of prokaryotic names with standing in nomenclature (LPSN) moves to the DSMZ. International Journal of Systematic and Evolutionary Microbiology, [S. I.], v. 70, p. 5607-5612, 2020.

LORENZI, H.; MATOS, F. J. A. Plantas medicinais no Brasil: nativas e exóticas. 2. ed. Nova Odessa: Instituto Plantarum, 2008.

LORENZONI, Luciana de Souza; BERNARDO, Flávia P. A.; MOULIN, Tatiane; GANDINI, Simony M. S. Utilização do extrato bruto de eugenia uniflora L. (pitanga) em teste antibacteriano in 
AVALIAÇÃO ANTIMICROBIANA DA EFICÁCIA

DOS EXTRATOS HIDROALCÓLICOS DA PITANGUEIRA

E DA GOIABEIRA, IN VITRO, CONTRA

STAPHYLOCOCCUS AUREUS ISOLADOS DE MASTITE BOVINA
Alexandre Tourino Mendonça Glei dos Anjos de Carvalho Castro

Maria Clara Pereira Inácio

Miriam de Andrade Pereira

vitro. ENCONTRO LATINO AMERICANO DE INICIAÇÃO CIENTÍFICA, 15.; ENCONTRO LATINO AMERICANO DE PÓS-GRADUAÇÃO, 11., 2011, Espírito Santo. Anais [...]. Espírito Santo: Instituto Federal de Educação Ciência e Tecnologia do Espírito Santo, 2011. p. 1-5.

LORENZONI, Luciana de Souza; GANDINI, Simony M. S.; SOUZA, Tércio da Silva; SANTOS JUNIOR, Alexandre Cristiano; ULISSES, Alessandra de Fátima. Estudo fitoquímico e antibacteriano do extrato etanólico de eugenia uniflora L. (myrtaceae). Enciclopédia Biosfera, Centro Científico Conhecer, Goiânia, v. 9, n. 17, p. 2796-2810, 2013.

MAIA, Rodrigo Rafael et al. Estudos do efeito antimicrobiano do extrato da goiabeira (Psidium guajava LINN) sobre Staphylococcus aureus multirre-sistente. Rev. ACSA, [S. I.], v. 5, n. 1, p. 36-40, 2009.

MEDVEĎOVÁ, Alžbeta; VALÍk, Ĺubomír. Staphylococcus aureus: characterisation and quantitative growth description in milk and artisanal raw milk cheese production. In: EISSA, Ayman Amer. Structure and function of food engineering. [S. I.]: InTech, 2012. p. 71-102.

MENDONÇA, A. T. Efeito dos óleos essenciais de condimentos sobre o crescimento de staphylococcus aureus em ricota cremosa. 2004. Tese (Doutorado em Ciência dos Alimentos) - Universidade Federal de Lavras, Lavras, 2004.

MENDONÇA, Alexandre Tourino et al. A utilização dos extratos hidroalcoólico e alcoólico de eugenia uniflora L. como agente antibacteriano. Revista da Universidade Vale do Rio Verde, Três Corações, v. 14, n. 1, p. 826-833, 2016.

NASCIMENTO, André Luiz Dias Ribeiro. Ação antimicrobiana do extrato de eugenia uniflora L. (pitanga) sobre Staphylococcus aureus, Pseudomonas aeruginosa e Escherichia coli. 2013. Trabalho de Conclusão de Curso (bacharelado em Farmácia) - Universidade Estadual da Paraíba, Campina Grande, 2013.

NCCLS. Performance standards for antimicrobial disk susceptibility tests; approved standard - eighth edition: NCCLS document M2-A8. Pennsylvania: NCCLS, 2003.

PRESTES, Luciana de Souza. Atividade antimicrobiana in vitro e antidiarréica em modelo experimental de extratos de folhas de plantas da família Myrtacea. 2011. Tese (Doutorado em Veterinária) - Universidade Federal de Pelotas, Pelotas, 2011.

SAEKI, Erika Kushikawa et al. Mastite bovina por Staphylococcus aureus: sensibilidade às drogas antimicrobianas e ao extrato alcoólico de própolis. Acta Veterinaria Brasilica, [S. I.], v. 5, n. 3, p. 284-290, 2011.

SANTANA, Thiago Coelho de. Uso do extrato de folhas do Jatobá (Hymenaea martiana Hayne) na redução das contagens de Salmonella spp., Escherichia coli e Staphylococcus aureus em leite cru. 2015. Dissertação (Mestrado em em Agricultura e Biodiversidade) Universidade Federal de Sergipe, Sergipe, 2015. 
AVALIAÇÃO ANTIMICROBIANA DA EFICÁCIA

DOS EXTRATOS HIDROALCÓLICOS DA PITANGUEIRA

E DA GOIABEIRA, IN VITRO, CONTRA

STAPHYLOCOCCUS AUREUS ISOLADOS DE MASTITE BOVINA
Alexandre Tourino Mendonça Glei dos Anjos de Carvalho Castro

Maria Clara Pereira Inácio

Miriam de Andrade Pereira

SANTOS, André Luis et al. Staphylococcus aureus: visitando uma cepa de importância hospitalar. Jornal Brasileiro de Patologia e Medicina Laboratorial, [S. I.], v. 43, n. 6, p. 413423, 2007.

SILVEIRA, Luiz Mário da Silva et al. Metodologias de atividade antimicrobiana aplicadas a extratos de plantas: comparação entre duas técnicas de ágar difusão. Rev. Bras. Farm, [S. I.], v. 90, n. 2, p. 124-128, 2009.

STIEVEN, A. C.; MOREIRA, J. J. S.; SILVA, C. F. Óleos essenciais de uvaia (Eugenia pyriformis Cam-bess): avaliação das atividades microbiana e antioxidan-te. Eclética Química, [S. I.], v. 34, n. 3, p. 7-13, 2009.

ZHANG, W. J. et al. Mechanism of quercetin as an antidiarrheal agent. Academic journal of the first medical college of PLA, [S. I.], v. 23, n. 10, p. 1029-1031, 2003. 